\title{
Overt Diabetes Induced by Overeating in Neonatally STZ-Treated Impaired Glucose Tolerant Mice : Long-Term Follow Up Study
}

\author{
Goji HASEGAWA, Hiroshi MORI, Manabu SAWADA, Shuichi TAKAGI, \\ Hirohumi SHIGETA, Yoshihiro KITAGAWA*, Koji NAKANO, \\ TAKAHIRO KANATSUNA AND MOTOHARU KONDO \\ 1st Department of Internal Medicine, Kyoto Prefectural University of \\ Medicine, Kyoto, Japan \\ *Department of Hemato-Endocrinology, Hospital of \\ West Japan Railways, Osaka, Japan
}

\begin{abstract}
This study has investigated the effect of a long period of overeating on the glycemic control and pancreatic $\beta$-cell function in neonatally streptozocin treated impaired glucose tolerant mice. Neonatally streptozocin $(60 \mathrm{mg} / \mathrm{kg})$ treated male ICR mice with $150-200 \mathrm{mg} / \mathrm{dl}$ of fed blood glucose levels were divided into two groups at 6 weeks of age. One group was maintained on a cafeteria diet (SZC) and the other on ordinary mouse chow (SZ) until 30 weeks of age. Normal male ICR mice were divided into a cafeteria diet group (CC) and an ordinary chow group (Cont). SZC and CC consumed $134-124 \%$ of the caloric intake in SZ and Cont throughout the study. Marked elevation of the fed blood glucose level was observed and the glucose tolerance was progressively impaired in SZC. On pancreas perfusion at 30 weeks of age, insulin secretion to $30 \mathrm{mM}$ glucose in SZC was significantly decreased compared with that in SZ. That in CC was slightly decreased compared with that in Cont. The pancreatic insulin concentration in SZC was significantly less than that in SZ. We conclude that chronic hyperglycemia, induced by the long period of overeating, accelerated the selective loss of $\beta$-cell sensitivity to glucose. Even in normal mice that did not have marked hyperglycemia, insulin secretion to glucose was suppressed, probably by chronic stimulation of the $\beta$-cell due to the long period of dietary excess.
\end{abstract}

Hyperglycemia in diabetics could become a secondary pathogenic factor and aggravate

Received December 27, 1988

Address to correspondence : GoJI HASEGAWA M. D. 1st Department of Internal Medicine, Kyoto Prefectural University of Medicine, Kawaramachi-Hirokoji, Kamikyoku, Kyoto 602, Japan. their impaired insulin secretion (Dohan and Lukens, 1947 ; Gravey et al., 1985 ; Unger and Grundy, 1985 ; Kergoat et al., 1987). Recently, Imamura et al. (1988) reported that sustained hyperglycemia, which was induced in partially pancreatectomized nondiabetic dogs by the continuous intravenous infusion of glucose, caused an insulin de- 
pendent diabetic state. Whether a similar phenomenon might occur in patients with poorly controlled non-insulin dependent diabetes (NIDDM) is of great interest.

Overeating is one of the risk factors in the development of human NIDDM. We have already reported that overt diabetes is induced by overeating in neonatally streptozocin (STZ) treated impaired glucose tolerant (IGT) mice, using a rather physiological dietary manipulation (Mori et al., 1987). In this study, we evaluated the effect of a longer period of overeating on glycemic control and pancreatic $\beta$-cell function, using a pancreas perfusion technique, in these IGT mice.

\section{Materials and Methods}

Two-day-old male ICR mice (Charles River Japan, Tokyo, Japan) received $60 \mathrm{mg} / \mathrm{kg}$ STZ (Upjohn, Kalamazoo, USA) intraperitoneally, and control mice received the dilutant, citrate buffer, $\mathrm{pH}$ 4.5. At 6 weeks of age, STZ treated mice, whose fed blood glucose levels were 150$200 \mathrm{mg} / \mathrm{d} 1$, were selected for the study and divided into two groups. One group was maintained on a cafeteria diet (SZC) and the other on ordinary mouse chow (SZ). Control mice were also divided into the cafeteria diet group (CC) and ordinary chow group (Cont). All mice were kept on their diets ad libitum until 30 weeks of age, and had free access to tap water. They were housed in a temperaturecontrolled room $\left(20-23^{\circ} \mathrm{C}\right)$ with a 12-hour light/ dark cycle.

Ordinary mouse chow $(3.6 \mathrm{kcal} / \mathrm{g}$ : Oriental Yeast, Tokyo, Japan) contained $60.6 \%$ carbohydrate, $26.7 \%$ protein and $12.7 \%$ fat by calories. The cafeteria diet was a mixture of chocolate, cookies and ordinary mouse chow $(4.0 \mathrm{kcal} / \mathrm{g})$ and contained approximately $57.7 \%$ carbohydrate, $19.5 \%$ protein and $22.8 \%$ fat by calories.

The body weight and fed blood glucose $(0900$ to $1100 \mathrm{~h})$ were measured every 2 weeks. $\mathrm{HbA}_{1 \mathrm{C}}$, specific for mouse and rat, was measured at 15,20 and 30 weeks of age according to the HPLC method (Kondo et al., 1988). The glucose tolerance test was performed at 10,20 and
30 weeks of age. The mice were fasted overnight and were injected intraperitoneally with a $20 \%$ glucose solution in a dose of $2 \mathrm{mg} / \mathrm{g} \cdot \mathrm{BW}$. Blood samples were collected at 0, 30,60 and 120 minutes after the injection. All blood samples were obtained from the orbital vein plexus and glucose was measured by the glucose oxidase method (FUJI DRI-CHEM SYSTEM, Fuji medical System Co., Tokyo Japan). Urine glucose was examined by the use of TESTAPE ${ }^{\circledR}$ (ELI LILLY Co., Indianapolis, USA) from fed mice. Measurement of food consumption (expressed as $\mathrm{kcal} /$ mouse/day) was done three times each week during the first 4 weeks, and three times every 2 weeks thereafter.

At 30 weeks of age, pancreas perfusion was performed according to the method of Grodsky and Franska (1975) as well as Bonnevie-Nielsen et al. (1981). Briefly, the mice were fasted overnight and anesthetized by an intraperitoneal injection of sodium pentobarbital $(80 \mathrm{mg} / \mathrm{kg}$. BW). After ligating the arteries around the pancreas (the superior mesenteric artery, the hepatic artery and the splenic artery), the celiac trunk was perfused through a catheter placed in the aorta. The basal perfusate was KrebsRinger bicarbonate buffer ( $\mathrm{pH}$ 7.4) with $1 \%$ bovine serum albumin (Miles Laboratories, Elkhart, USA), 3\% Dextran T70 (Pharmacia, Uppsala, Sweden) and $5 \mathrm{mM}$ glucose, equilibrated with a continuous supply of $95 \% \mathrm{O}_{2} / 5 \%$ $\mathrm{CO}_{2}$ gas. The pancreas was perfused at $37^{\circ} \mathrm{C}$, at a flow rate of $0.6 \mathrm{ml} / \mathrm{min}$. After 20 minutes of equilibration with the basal perfusate, the pancreas was stimulated with $30 \mathrm{mM}$ glucose for 10 minutes. The pancreas was reequilibrated with basal perfusate for 10 minutes, and then stimulated with a combination of $5 \mathrm{mM}$ glucose and $19 \mathrm{mM}$ arginine for 10 minutes. Individual samples, collected from the portal vein at 1or 2-minute intervals were frozen immediately and stored at $-20^{\circ} \mathrm{C}$.

After the perfusion, a part of the pancreas tail was fixed in $10 \%$ formalin solution for microscopic study. The rest of the pancreas was homogenized in acid-alcohol solution $(75 \%$ $\mathrm{vol} / \mathrm{vol}$ of ethanol, $1.5 \% \mathrm{vol} / \mathrm{vol}$ of $11.6 \mathrm{~mol} / \mathrm{L}$ $\mathrm{HCl}$ and distilled water) for the measurement of the insulin concentration. For light microscopy, the pancreas was embedded in paraffin and sequentially sectioned. These sections were stained with hematoxylin and eosin, and by the immunoperoxidase method with primary anti- 
bodies to insulin ( $\beta$-cell) and glucagon ( $\alpha$-cell).

Insulin in the perfusate and the pancreas was assayed by the solid phase radioimmunoassay (insulin RIA kit, Dinabot Radioisotope Lab., Tokyo, Japan). The insulin release from perfused pancreas per minute was expressed as $\mu \mathrm{U} / \mathrm{min}$, multiplying the insulin concentration of each samples by the flow rate. The total insulin release was calculated by adding the insulin release per minute during the perfusate condition and expressed as $\mu \mathrm{U} / 10 \mathrm{~min}$.

The results are shown as the mean \pm SEM. To evaluate the effect of cafeteria diet feeding in STZ treated IGT mice and normal mice, this study allowed the following comparisons: SZC vs $\mathrm{SZ}$ and $\mathrm{CC}$ vs Cont. Student's $t$-test was used to test for significant differences between these two groups. Comparisons involving four groups were made by analysis of variance (ANOVA).

\section{Results}

The mean caloric intake/mouse/day in

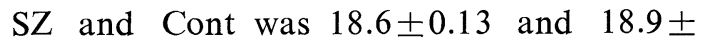
$0.19 \mathrm{kcal}$, respectively, and remained constant throughout the study. SZC and CC consumed $25.0 \pm 0.58(134 \%$ of that in SZ) and $24.9 \pm 1.05 \mathrm{kcal}(132 \%$ of that in Cont), respectively, during the first 12 weeks on the cafeteria diet. Thereafter, they decreased slightly, but maintained 125$128 \%$ of the caloric intake in $\mathrm{SZ}$ and Cont $(\mathrm{P}<0.001$ : SZC vs $\mathrm{SZ}, \mathrm{P}<0.01$ : $\mathrm{CC}$ vs Cont).

The body weight gain in the mice on the cafeteria diet was significantly greater than that in those on ordinary mouse chow ( $P<0.01$ : SZC vs SZ, $\mathrm{P}<0.02$ : $\mathrm{CC}$ vs Cont at 30 weeks of age. Fig. 1).

The fed blood glucose level (Fig. 2) in SZC markedly increased after 4 weeks of cafeteria diet feeding, averaging 270.4士 $19.5 \mathrm{mg} / \mathrm{d} 1$. On the other hand, that in $\mathrm{SZ}$ at 10 weeks of age was $205.8 \pm 2.7 \mathrm{mg} / \mathrm{d} 1$ $(\mathrm{P}<0.02)$. Thereafter, the fed blood glucose concentration in SZC decreased slightly, but it was maintained at a significantly higher level than that in SZ within the time period studied. Fed blood glucose in $\mathrm{CC}$ increased slightly compared with that in Cont after 10 weeks of cafeteria

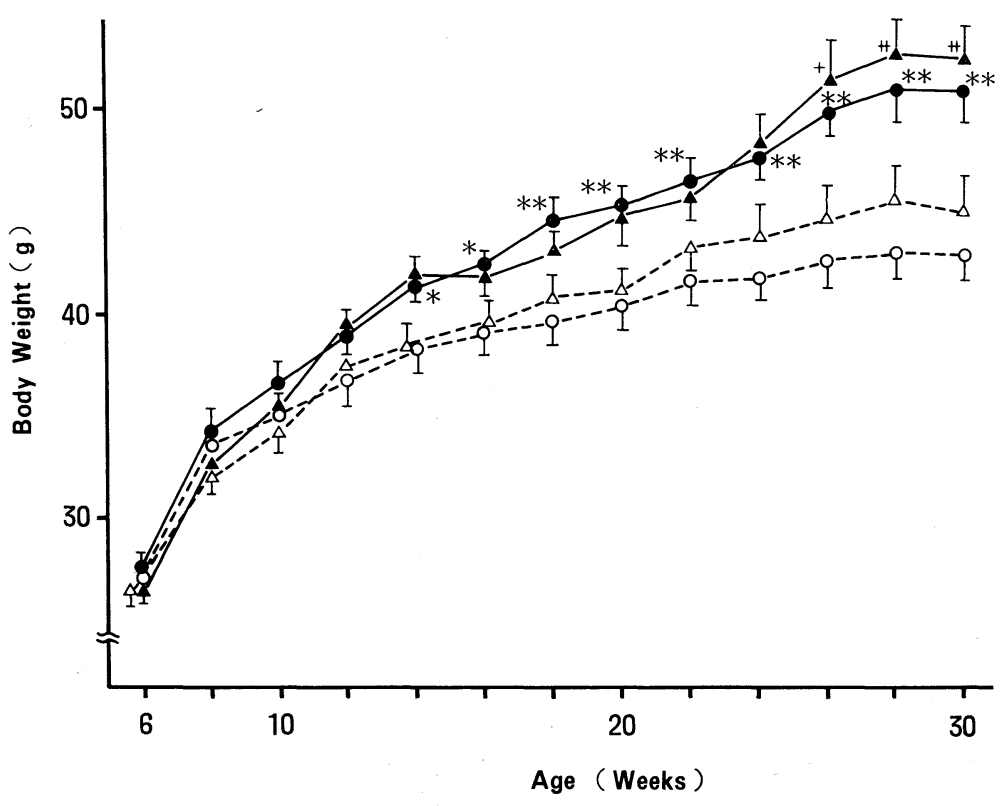

Fig. 1. Effect of long term cafeteria diet on body weight. Cafeteria diet was fed to SZC and CC from 6 weeks of age. Values represent mean \pm SEM.

$$
\begin{aligned}
& \triangle \cdots \cdots, \text { Cont }(\mathrm{n}=5) \\
& \triangle \longrightarrow, C C(n=5) \\
& \text { …..., SZ }(\mathrm{n}=6) \\
& \text {-—, SZC }(n=7) \\
& * \mathrm{P}<.05 \\
& * * \mathrm{P}<.01 \text { vs } \mathrm{SZ} \\
& +\mathrm{P}<.05 \\
& { }^{++} \mathrm{P}<.02 \text { vs Cont }
\end{aligned}
$$




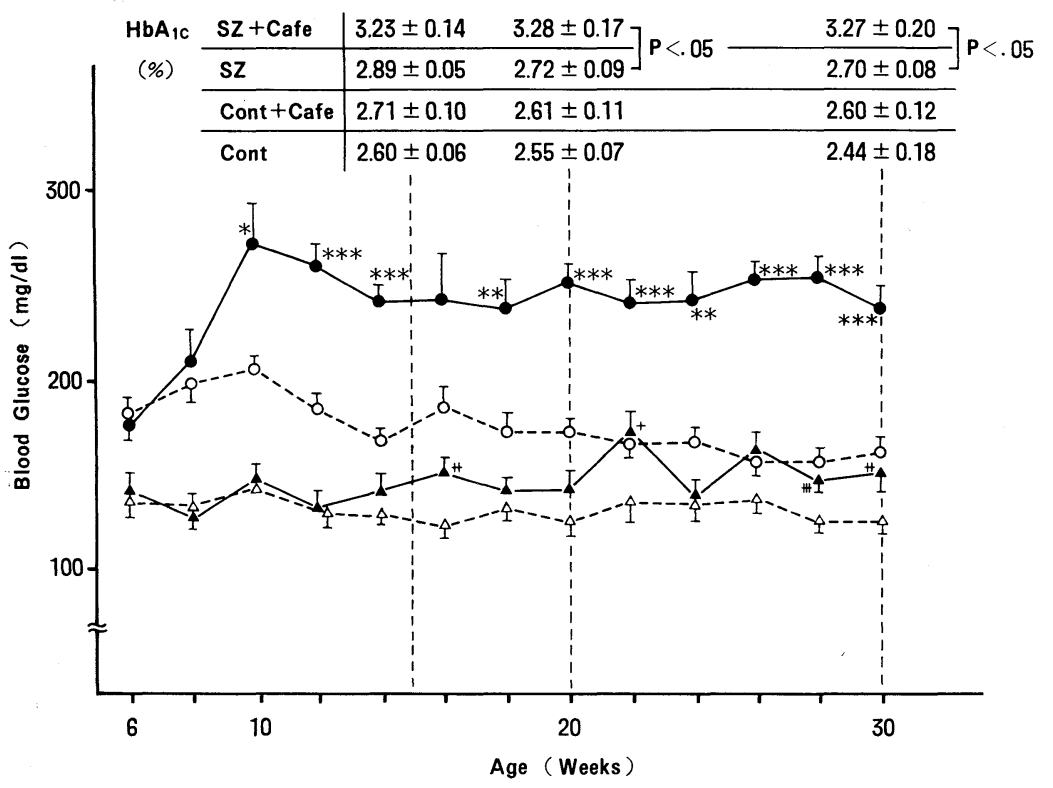

August 1989

Fig. 2. Effect of long term cafeteria diet on fed blood glucose and $\mathrm{HbA}_{1 \mathrm{c}}$. Cafeteria diet was fed to SZC and CC from 6 weeks of age. Values represent mean \pm SEM.

$\triangle \cdots \cdots$, Cont $(n=5)$

$\Delta \longrightarrow$, CC $(n=5)$

…..., SZ $(n=6)$

- , SZC $(\mathrm{n}=7)$

$* \mathrm{P}<.02$

$* * \mathrm{P}<.01$

$* * * \mathrm{P}<.001$ vs $\mathrm{SZ}$

$+\mathrm{P}<.05$

$++\mathrm{P}<.02$

${ }^{+++} \mathbf{P}<.01$ vs Cont diet feeding. Glucosuria was frequently detected only in SZC.

The $\mathrm{HbA}_{1 \mathrm{C}}$ levels (Fig. 2) well reflected the profile of the fed blood glucose concentration in each group. The mice in the cafeteria diet groups had higher $\mathrm{HbA}_{1 \mathrm{C}}$ than in the ordinary chow groups. However, $\mathrm{HbA}_{1 \mathrm{C}}$ did not increase progressively throughout the study.

Glucose tolerance was impaired by cafeteria diet feeding. The longer the period of overeating, the more apparent became the impaired glucose tolerance in the mice on the cafeteria diet (Fig. 3).

On pancreas perfusion at 30 weeks of age (Fig. 4), the insulin secretion to $30 \mathrm{mM}$ glucose was markedly suppressed in the STZ treated groups (SZC and SZ), whereas insulin secretion to $19 \mathrm{mM}$ arginine was relatively well maintained compared to that in controls (ANOVA : not significant). The insulin secretion to $30 \mathrm{mM}$ glucose in SZC was significantly less than that in $\mathrm{SZ}$ at all points. Also in $\mathrm{CC}$, the insulin secretion to $30 \mathrm{mM}$ glucose was slightly suppressed compared to that in Cont, and the insulin secretion to the basal perfusate was greater than that in Cont. Total insulin release to $30 \mathrm{mM}$ glucose in SZC and CC was significantly decreased compared with that in SZ and Cont (Table 1, P $<0.001$ : SZC vs $\mathrm{SZ}, \mathrm{P}<0.05$ : $\mathrm{CC}$ vs Cont).

The pancreatic insulin concentration in SZC significantly decreased compared with that in SZ (Table $1, \mathrm{P}<0.01$ ). That in $\mathrm{CC}$ slightly decreased compared with that in Cont, although there were no significant differences between the two groups.

In the histological study, the $\beta$-cells of SZC and SZ were scattered throughout the islet, whereas the $\alpha$-cells were usually found at the periphery of the islet as in the normal islets observed in Cont, and there were no differences between SZC and SZ. Also, there were no histological differences between Cont and $\mathrm{CC}$.

\section{Discussion}

As shown in the earlier studies on neonatally STZ treated diabetic rats (Weir 

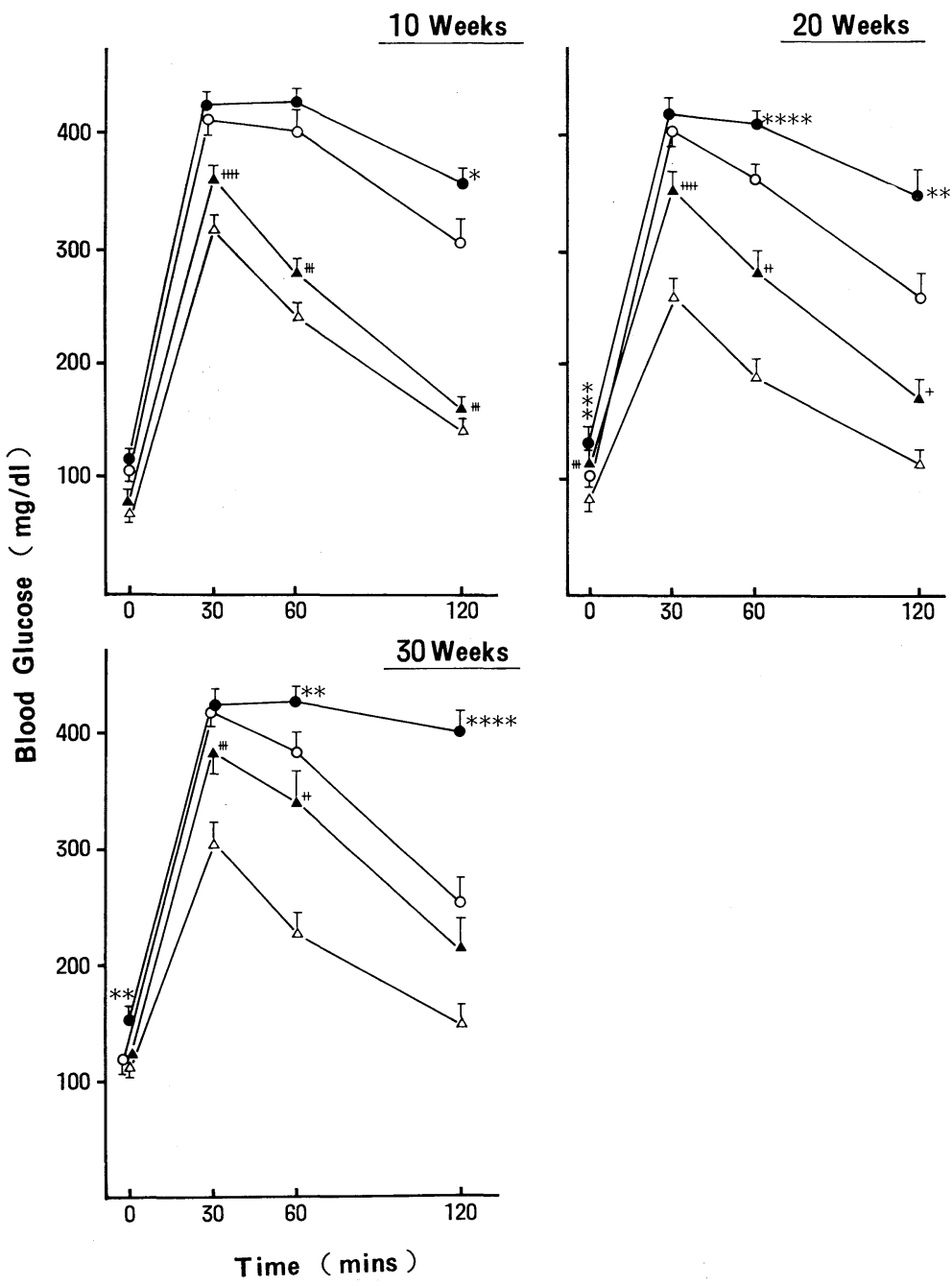

Fig. 3. Change in glucose tolerance during cafeteria diet. Cafeteria diet was fed to SZC and CC from 6 weeks of age. Mice, fasted overnight, were administered $2 \mathrm{mg} / \mathrm{g}$ • BW glucose intraperitoneally at 0 time. Values represent mean \pm SEM.

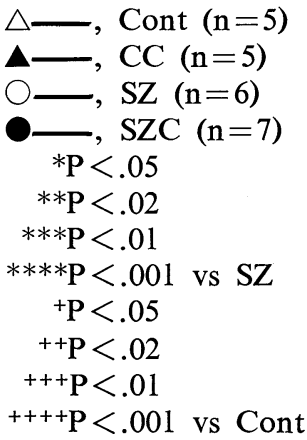

Table 1. Insulin release from perfused pancreas, and pancreatic insulin concentration.

\begin{tabular}{|c|c|c|c|}
\hline \multirow[b]{2}{*}{ Group $(\mathrm{N})$} & \multicolumn{2}{|c|}{ Total insulin release $(\mu \mathrm{U} / 10 \mathrm{~min})$} & \multirow{2}{*}{$\begin{array}{c}\text { Insulin } \\
\text { concentration } \\
\text { (U/g. pancreas) }\end{array}$} \\
\hline & $30 \mathrm{mM}$ Glucose & $19 \mathrm{mM}$ Arginine & \\
\hline SZ & $157.0 \pm 11.1$ & $292.2 \pm 20.1$ & $0.43 \pm 0.01$ \\
\hline SZC (7) & $98.4 \pm 5.9 * *$ & $279.2 \pm 13.0$ & $0.35 \pm 0.01 *$ \\
\hline Cont (5) & $432.2 \pm 32.3$ & $319.4 \pm 36.2$ & $0.92 \pm 0.05$ \\
\hline $\mathrm{CC} \quad$ (5) & $332.2 \pm 17.0^{+}$ & $308.9 \pm 52.0$ & $0.79 \pm 0.07$ \\
\hline
\end{tabular}

Values are shown as mean \pm SEM.

$* \mathbf{P}<.01, \quad * * \mathrm{P}<.001$ vs $\mathrm{SZ}$

$+\mathrm{P}<.05$ vs Cont

\# ANOVA : not significant $(\mathrm{P}>.5)$ 


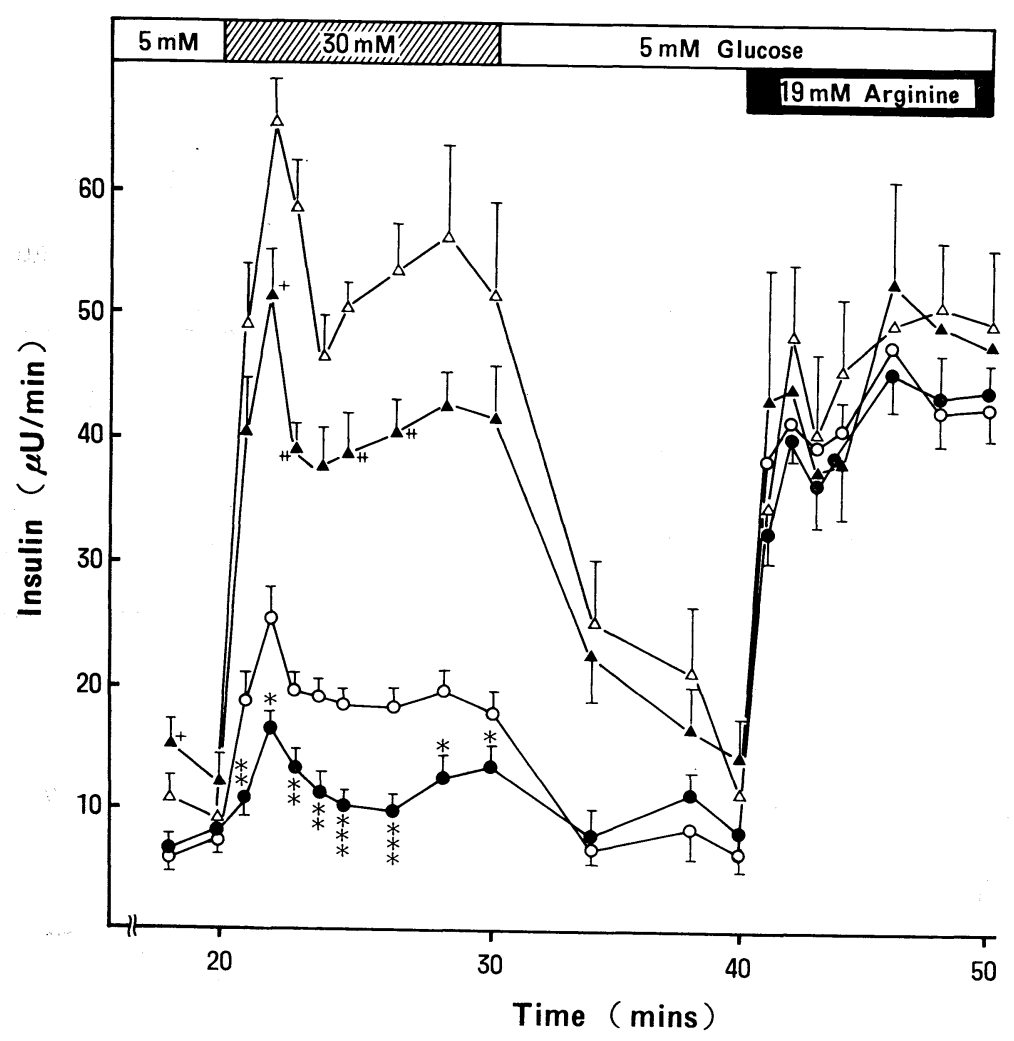

Fig. 4. Effect of long term cafeteria diet on insulin response to 30 $\mathrm{mM}$ glucose and 19 $\mathrm{mM}$ arginine during pancreas perfusion. The pancreas perfusion was performed at 30 weeks of age. Values represent mean \pm SEM. The insulin secretion to $19 \mathrm{mM}$ arginine was not significantly different between the groups at all points (ANOVA, P > .4).

$\triangle \longrightarrow$, Cont $(\mathrm{n}=5)$

$\triangle \longrightarrow, \mathrm{CC}(\mathrm{n}=5)$

$\bigcirc-, S Z(n=6)$

- , SZC $(\mathrm{n}=7)$

$* \mathrm{P}<.02$

$* * \mathrm{P}<.01$

$* * * \mathrm{P}<.001$ vs $\mathrm{SZ}$

$+\mathrm{P}<.05$

${ }^{++} \mathrm{P}<.02$ vs Cont

et al., 1981; Giroix et al., 1983), adult mice treated with streptozocin at birth exhibited a diabetic state similar to that observed in NIDDM with specific failure of insulin release to glucose, as characterized in the perfused pancreas study (Kano et al., 1985).

In this study, overeating caused by the cafeteria diet induced overt diabetes in neonatally STZ treated IGT mice. This finding is consistent with our previous report (Mori et al., 1987). Overt diabetes might be provoked because the reduced $\beta$-cell mass in STZ treated IGT mice could not compensate for the increased insulin demand due to dietary excess. The fed blood glucose concentration remained high and glucose tolerance deteriorated in SZC due to the long period of overeating. These results may be induced by increased insulin resistance due to body weight gain and decreased insulin secretion to glucose. However, the fed blood glucose and $\mathrm{HbA}_{1 \mathrm{C}}$ did not progressively increase, because these mice could secrete insulin to nonglucose stimuli (amino acid), but not to glucose as the following shows. Therefore, body weight loss, one of the symptomatic markers of severe diabetes, was not observed in the overt diabetic mice.

Insulin secretion to glucose from the perfused pancreas at 30 weeks of age was significantly suppressed in these overt diabetic mice, whereas insulin secretion to arginine was well preserved compared to that in the control mice. In our previous report (Mori et al., 1987), overt diabetic mice induced by a 4-week cafeteria diet 
demonstrated less insulin secretion to glucose than that in the IGT mice fed ordinary mouse chow, but there were no significant differences between the two group. Decreased glucose stimulated insulin secretion during chronic glucose exposure has been reported both in vitro (Lacy et al., 1976; Bolaffi et al., 1986; Curry, 1986; Hoening et al., 1986) and in vivo (Leahy et al., 1986). Therefore, diabetic hyperglycemia, once established, may itself become a secondary pathogenic factor and aggravate $\beta$-cell dysfunction. The present study indicated that the chronic hyperglycemia, produced by the long period of overeating in neonatally STZ treated IGT mice, could accelerate the selective loss of $\beta$-cell sensitivity to glucose.

It is well recognized that in insulindependent diabetes (IDDM) there is virtually no glucose stimulated insulin secretion and there is greatly decreased or nonexistent insulin response to nonglucose stimuli. Also in NOD mouse, the murine equivalent of IDDM, Kano et al. (1986) showed that insulin secretion to arginine from the perfused pancreas decreased with the development of insulitis and a reduction in the number of pancreatic islets. The pattern of insulin response in the present overt diabetic mice was essentially different from that shown in NOD mouse at the onset of diabetes. In the histological study, the loss of pancreatic $\beta$-cells in the present overt diabetic mice was not different from that in IGT mice.

Recently, Imamura et al. (1988) demonstrated that severe diabetes was induced by means of intravenous glucose infusion in subtotally depancreatized but non-diabetic $\operatorname{dogs}$ as a result of rapid $\beta$-cell depletion. They exhibited similar ketonuria and severe body weight loss to that observed in human IDDM. A similar mechanism might operate as a consequence of chronic hyperglycemia of poorly controlled human NIDDM. It is well recognized that glucose is the most potent stimulator of insulin release. Therefore, whether chronic hyperglycemia, found in poorly controlled diabetic patients due to diet failure, has the same effect on $\beta$ cells as that induced by enormous glucose overloading intravenously remains questionable. In the present study, we have focused our attention on overeating as an important factor in the development of NIDDM, and succeeded in creating a poorly controlled diabetic state in neonatally STZ treated IGT mice by physiological dietary manipulation. Sustained hyperglycemia induced by overeating in these mice could not produce $\beta$-cell depletion. However, it remains possible that a longer period of overeating may cause $\beta$-cell depletion at a rather slow rate.

The present study indicated that the long period of overeating induced loss of insulin secretion to glucose on pancreas perfusion even in the normal mice. Leahy et al. (1986) have reported that glucose stimulated insulin secretion is partially lost in normal rats made markedly hyperglycemic for $48-\mathrm{hr}$ with continuous glucose infusion. The present results suggest that, without marked hyperglycemia, chronic stimulation of $\beta$-cells due to increased insulin demand following dietary excess or body weight gain might induce selective insensitivity to glucose. Normal mice kept on the cafeteria diet had a slightly higher blood glucose level than the mice on ordinary mouse chow (CC: $150 \pm 6.9$, Cont : 124 $\pm 3.9 \mathrm{mg} / \mathrm{dl}$ at 30 weeks of age. $\mathrm{P}<0.02$ ). Therefore, the range of blood glucose levels in which $\beta$-cell function is normal might be very narrow (Kergoat et al., 1987).

The pancreatic insulin concentration in overt diabetic mice was significantly reduced compared with that in IGT mice. Regulation of the pancreatic insulin concentration remains poorly understood. In the overt diabetic mice, the rate of insulin secretion might exceed that of insulin biosynthesis due to overeating. Hyperglycemia has been 
felt to have the long-term effect of suppressing insulin synthesis (Orland et al., 1985). The pancreatic insulin concentrations in the overt diabetic mice and the control mice differed considerably even though insulin secretion to arginine was not very dissimilar. Thus it is suspected that $\beta$-cell secretory capacity may not be determined by the pancreatic insulin concentration.

In conclusion, overt diabetes was induced by overeating in neonatally STZ treated IGT mice. A longer period of overeating caused sustained hyperglycemia and deterioration of glucose tolerance. Furthermore, it accelerated the selective loss of $\beta$-cell sensitivity to glucose, but did not result in $\beta$-cell depletion. Even in the normal mice, the insulin secretion in response to glucose was suppressed probably by chronic stimulation of the $\beta$-cells due to the long period of overeating. By varying the duration of overeating, this NIDDM model mouse, induced by overeating, would provide a useful way to study the abnormal $\beta$-cell function found in human NIDDM.

\section{Acknowledgement}

This study was supported by a grant from the Sunflower Public Welfare Foundation, Tokyo, Japan.

\section{References}

Bolaffi, J. L., A. Heldt, L. D. Lewis and G. M. Grodsky (1986). The third phase of in vitro insulin secretion: evidence for glucose insensitivity. Diabetes 35, 370-373.

Bonnevie-Nielsen, V., M. W. Steffes and A. Lernmark (1981). A major loss in islet mass and B-cell function precedes hyperglycemia. Diabetes 30, 424-429.

Curry, D. L. (1986). Insulin content and insulino-genesis by the perfused rat pancreas: effects of long term glucose stimulation. Endocrinology 118, 170-175.
Dohan, F. C. and F. E. W. Lukens (1947). Lesions of the pancreatic islets produced in cats by administration of glucose. Science 105, 183.

Garvey, W. T., J. M. Olefsky, J. Griffin, R. F. Hamman and O. G. Kolterman (1985). The effect of insulin treatment on insulin secretion and insulin action in type II diabetes mellitus. Diabetes 34, 222-234.

Giroix, M. H., B. Portha, M. Kergoat, D. Bailbe and L. Picon (1983). Glucose insensitivity and amino-acid hypersensitivity of insulin release in rats with non-insulin dependent diabetes: A study with the perfused pancreas. Diabetes 32, 445-451.

Grodsky, G. M. and R. E. Franska (1975). The in vitro perfused pancreas. In : Methods in enzymology (J. G. Hardman and B. W. O'Malley ed.). Academic Press, New York. pp. 763-788.

Hoenig, M., L. C. MacGregor and F. M. Matschinsky (1986). In vitro exhaustion of pancreatic B-cells. Am. J. Physiol. 250, E502511.

Imamura, T., M. Koffler, J. H. Helderman, D. Prince, R. Thirlby, L. Inman and R. H. Unger (1988). Severe diabetes induced in subtotally depancreatized dogs by sustained hyperglycemia. Diabetes 37, 600-609.

Kano, Y., Y. Kitagawa, H. Mori, S. Kajiyama, M. Nakai, H. Shigeta, H. Nishioka, T. Yoshida, T. Kanatsuna and M. Kondo (1985). Mouse with impaired glucose tolerance treated with streptozotocin in the neonatal period. Discrepancy between glucose and arginine induced insulin secretion. In : Peptide Hormones in pancreas 5 (K. Shima ed.), Biomedical Research Foundation, Tokyo, pp. 163-170. (in Japanese)

Kano, Y., T. Kanatsuna, N. Nakamura, Y. Kitagawa, H. Mori, S. Kajiyama, N. Nakano and M. Kondo (1986). Defect of the firstphase insulin secretion to glucose stimulation in the perfused pancreas of the nonobese diabetic (NOD) mouse. Diabetes 35, 486490.

Kergoat, M., D. Bailbe and B. Portha (1987). Insulin treatment improves glucose-induced insulin release in rats with NIDDM induced by streptozocin. Diabetes 36, 971-977.

Kondo, N., K. Ohara, K. Ienaga, K. Nakano and T. Kanatsuna (1988). Assay of $\mathrm{HbA}_{1 \mathrm{C}}$, specific for mice and rats, using HPLC. $J$. 
Japan Diab. Soc. 31 (Sppl. 1), 222. (in Orland, M. J. R., R. Chyn and M. A. Permutt Japanese)

Lacy, P. E., B. S. Finke, B. A. Conant and S. (1985). Modulation of proinsulin messenger Nabu (1976). Long-term perifusion of isolated rat islets in vitro. Diabetes 25, 484-493.

Leahy, J. L., H. E. Cooper, D. A. Deal and G. C. Weir (1986). Chronic hyperglycemia is associated with impaired glucose influence on insulin secretion: a study in normal rats using chronic in vitro glucose infusions. $J$. Clin. Invest. 77, 908-915.

RNA after partial pancreatectomies in rats: relationship to glucose homeostasis. J. Clin. Invest. 75, 2047-2055.

Unger, R. H. and S. Grundy (1985). Hyperglycaemia as an inducer as well as a consequence of impaired islet cell function and insulin resistance: implications for the management of diabetes. Diabetologia 28, 119121.

Mori, H., Y. Kitagawa, Y. Kano, M. Nakai, H. Shigeta, K. Nakano and T. Kanatsuna (1987). Overeating can induce overt diabetes in neonatally streptozotocin treated IGT-mice. Diabetes 36 (Suppl. 1), 22.

Weir, G. C., E. T. Clore, C. J. Zmachinski and S. Bonner-Weir (1981). Islet secretion in a new experimental model for non-insulindependent diabetes. Diabetes 30, 590-595. 